Hipotenusa : Journal of Mathematical Society

Volume 3 Issue 1 Year 2021

ISSN: $2716-3156$

Website: https://hipotenusa.iainsalatiga.ac.id/index.php/hipotenusa/index

\title{
Analysis of Mathematics National Exam Questions based on TIMSS Taxonomy
}

\author{
Nur Colis \\ Mathematics Education Department IAIN Salatiga, Indonesia \\ *Corresponding Author, e-mail: colis288@gmail.com \\ DOI: $10.18326 /$ hipotenusa.v3i1.25-51
}

\begin{abstract}
Article submitted
: July 3, 2020

Article reviewed

: October 4, 2020

Article published

: June 1, 2021
\end{abstract}

\begin{abstract}
The purpose of this research was to find out the spread out content and cognitive dimension of the question of Mathematics National Exam for Junior High School (SMP) / Islamic Junior High School (MTs) in the school year of 2005/2006-2018/2019 and find out the suitability question of Mathematics Final Exam in Junior High School based on government guidelines and TIMSS taxonomy. This type of research is a qualitative approach. This research use collection data with document analysis. Data analysis techniques consist of data reduction, data display, and verification. The research subjects were in the form of 14 SMP / MTs national mathematics exam texts from the 2005/2006 to 2018/2019 academic year. The indicators of content dimensions and cognitive dimensions used are based on the TIMSS taxonomy. Checking the validity of the data, the researcher uses a triangulation by an expert through Online FGD (Focus Group Discussion).

The research result as follows: 1. An analysis a question of Mathematics Final Exam in Junior High School in the school year of 2005/2006-2018/2019 based on a taxonomy TIMSS obtain results that percentage spread of content and cognitive dimension still not appropriate yet with TIMSS Assessment Framework. At the content dimension, the spread of a question dominated by geometry domain while data and probability have spread of a question very few. Then, algebra and number domain pretty close proportion which have been specified by TIMSS. 2. the question of Mathematics Final Exam in Junior High School to the scope of material which set by the government was not given percentage distribution of materials obviously while cognitive level from government obtains a result that different with findings result in the researcher based on TIMSS taxonomy because there is different definition at government cognitive level from with TIMSS cognitive domain. There is a question that includes an application in government cognitive level however it includes knowing domain based on TIMSS taxonomy. Suitability a question of Final Exam from the school year of 2005/2006 till 2018/2019 indicate there are percentages increase from year to year close appropriate to proportion TIMSS Assessment Framework. It shows the percentage each other domain close proportion TIMSS in content and cognitive dimension.
\end{abstract}

Keywords: analysis of question, mathematics national exam, TIMSS taxonomy

Hipotenusa is licensed under a Creative Commons Attribution-ShareAlike 4.0 International License. 


\section{Hipotenusa Journal, 3 (1), June 2021 \\ Nur Colis}

\section{INTRODUCTION}

TIMSS (Trends In International Mathematics and Science Study) is an international study organized by the International Association for the Evaluation of Education (IEA), which is an international association to assess Mathematical and Science achievements in Education (Hadi \& Novaliyosi, 2019). TIMSS will measure the achievements of students grade IV and VIII in mathematics and science of participating countries. For Indonesia, the benefits obtained include knowing the achievements of Indonesian students when compared to other students performances in other countries as well as knowing the factors that influence it. TIMSS aims at determining the improvement of mathematics and science learning where the framework for assessment of mathematics ability is assessed using terms of dimensions and domains (Pratiwi, 2016).

The basis of mathematical and science achievement assessments in TIMSS are categorized in two domains, namely the content and cognitive domain by considering the curriculum in the country. Content dimension consists of four domains, namely: numbers, algebra, geometry, data and opportunities. Each domain is further detailed on several topics (Mullis, I. V. S., Martin, 2019).

The proportion of ability that is assessed on the dimensions of the content are divided into four domains as follows: 1) Numbers (30\%) with the topic of whole number, fractions, decimals, and integers, ratios, proportions, and percent. 2) Algebra (30\%) with the topic of algebraic expression and operation, equations and inequality, relations and functions. 3) Geometry (20\%) with the topic of geometry forms, location and displacement. 4) Data and opportunities (20\%) with the topic of data characteristics, data interpretation, and opportunities.

The cognitive domain consists of three domains, they are knowing, applying and reasoning. Cognitive dimensions are defined as the expected behaviours of students when they are dealing with the mathematical domain included in the content dimension. The proportion of the ability tested on the cognitive dimension is divided into three domains as follows: 1) Knowing (35\%) with the topic of recall, recognize, classify / order, retrieves, and measure. 2) Applying (40\%) with the topic of determine, representatives / models, and implements. 3) Reasoning (25\%) with the topic of analyse, integrate / synthesize, evaluate, draw, generalize, and justify. 


\section{Hipotenusa Journal, 3 (1), June 2021 \\ Nur Colis}

Curriculum changes in schools or madrasas are very common in the educational world (Prastowo et al., 2018). In the history of primary and secondary education in Indonesia, there were at least 10 types of curriculum that were used. That curriculum that were applied and used since the era of post-independence to the current curriculum consists of: first, the lesson plan 1947; second, the 1952 curriculum; third, the 1964 curriculum; fourth, the 1968 curriculum; fifth, the 1975/1976 curriculum; sixth, the 1984 curriculum; seventh, the 1994 curriculum; eighth, the curriculum of 2002 and 2004; ninth, the 2006 educational unit curriculum (KTSP); and tenth, 2013 curriculum.

The role of the government to improve the education system in Indonesia is by changing the curriculum. (Prasetyo \& Rudhito, 2016) stated that the rationale behind the launching of the 2013 curriculum policy was the low competency of human resources as reflected in the results of the TIMSS (Trends International Mathematics and Science) where the international mathematical competency test results placed Indonesia in the lower ranking.

The implementation of the 2013 curriculum (Kemendikbud, 2013a) requires competency-based assessment includes attitude, knowledge, skills that are integrated with the learning process and make a portfolio as the main instrument (Sumaryono, 2016). The main purpose of mathematics learning in junior high school / MTs (Kemendikbud, 2013a) is that the students can develop attitudes, understanding and skills that are in accordance with the characteristics of mathematics. In the case of developing attitudes, students are expected to be able to think critically, logically, analytic, and creative, to respect mathematics in life by growing curiosity, attention, and interest in studying mathematics, resilient and confidence in solving problems in their daily lives.

The 2013 curriculum emphasize the essence of the scientific approach in learning (Lestari, 2018). The scientific approach is believed to be a good way to develop attitudes, skills, and knowledge of students. This scientific education includes observing, questioning, trying, processing, presenting, concluding, and creating in all subjects. Those process of thinking is in accordance with the mathematical thinking where mathematics has a structure with a strong and clear relationship with others and has the deductive and consistent mindset.

These efforts from the government are aimed to improve the intelligence of students, especially in mathematics subjects, but international mathematics achievements 
in junior high school students is still low. (Mawarni, 2020) Data from the Research and Development of the Ministry of Education and Culture stated that significantly the achievements of Indonesian students of grade VIII were still far below the international average. Indonesia has participated as a participant in an international mathematics assessment event held every four years, TIMSS (Trends in International Mathematics and Science Study) from 1999 to 2019 . The achievement of mathematics continues to decline. In 1999, Indonesia was in the $34^{\text {th }}$ place out of 38 countries with a score of 403 , in 2003 , was in 35 of 46 countries with an average score of 411, in 2007 Indonesia was in 36 out of 49 countries with an average score of 397 and year 2011 was in the order of 38 out of 42 countries with an average score of 386 , and in 2015 Indonesia was in $44^{\text {th }}$ place out of 49 countries.

The learning outcomes indicators can be used as a basis for the assessment of students in achieving the expected learning outcomes and performance (Wulan \& Rusdiana, 2013). An assessment or evaluation is needed to find out the achievement of learning outcomes. The results of the evaluation can describe the progress of education itself, and more specifically, the quality of education from time to time. The results of the evaluation can also be used to compare the achievement of schools in one region or between regions.

In general, the purpose of learning evaluation is to determine the effectiveness and efficiency of the learning system (Asrul et al., 2014). The intended learning system includes objectives, material, methods, media, learning sources, environment and the assessment system. In addition, learning evaluation is also aimed at assessing the effectiveness of learning strategies, assessing and increasing the effectiveness of the curriculum program, assessing and increasing the effectiveness of learning, helping students in learning, identifying the strengths and weaknesses of students, and to providing data that helps teachers and stakeholders to make decisions.

The National Examination is a term for the assessment of national student competencies at the level of basic and secondary education. Reporting from the Kemendikbud Puspendik page (www.pusmenjar.kemdikbud.go.id, 2019A), the National Examination was held to measure the achievement of graduates students competencies at an education unit as a result of the learning process in accordance with the Standards Competency of Graduates (SKL). In addition, the National Examination can also be used 
to map the level of students' achievements at the respective education institution. This national exam is the peak point of the students' learning achievements for 6 years for the elementary school level and three years for the junior high school level (www.pusmenjar.kemdikbud.go.id, 2019b).

Whether or not the implementation of the curriculum succeeded, it can be seen from the success of the national examination, namely the students' ability to master the basic competencies stipulated in the curriculum according to the school level (Fahmi, 2011). The policy carried out by the government regarding national exams is basically an evaluation step to set a value standard to map the quality and competence of graduates. Therefore, the preparation of the Pre National Exam questions should consider which cognitive level to be measured in order to prepare the students for the real National Examination.

Lately, Indonesian students have rejoiced because the national examination is permanently abolished by the Minister of Education and Culture (Mendikbud) Nadiem Makarim in 2020 and replacing it with the assessment of minimum competencies and character surveys (Damaledo, 2019). He said the policy was a follow-up to President Joko Widodo's direction to improve the quality of human resources (HR). Meaning that starting from 2021, the assessment of minimum competency and character surveys will be carried out for the first time.

The Minister of Education and Culture said that the difficulty level of the National Examination would be the same as before (Aminah, 2021). Totok Suprayitno as Head of the Ministry of Education and Culture's Research and Development (Balitbang), at a press conference in Jakarta on March 21 2019, mentioned that there was no change in the distribution of difficulty level from the previous year. The composition of the question is based on the cognitive level, which is 10 to 15 percent for reasoning, 50 to 60 percent for applying and 25 to 30 percent for knowing and understanding. Totok explained what was tested in the National Examination is what should be taught in class. If there is a school that has not taught the materials, then they should teach the materials.

Totok said in recent years since the computer-based national exam (UNBK) was held, the average score of the National Examination fell. According to him, it is a true condition. The Ministry of Education and Culture hopes that the students' ability will increase from the previous year, which is currently a lot them still struggle with the low 
difficulty questions. If the proportion of cognitive distribution in percent is described into the number of questions, then the number of questions for knowing and understanding is 10 to12 questions, for the applying is 20 to 24 points while for reasoning is 4 to 6 items.

In the standard operational procedure of the National Examination academic year 2016/2017 chapter IV National Examination Material (Badan Standar Nasional Pendidikan, 2017) explained that (1) The National Exam materials guideline for academic year 2016/2017 is compiled based on the criteria to achieve graduates competencies, content standards, and the material scope in the applicable curriculum, (2) The National Exam materials guideline should contain cognitive and material scope. In the material guideline of mathematics in 2018/2019 exposed the scope of the material and cognitive level clearly, but the distribution of proportion of each material and each cognitive level on the National Examination question is not included at all.

The influence of TIMSS on Indonesian education is very high. It is reflected in the change of the national education policy as planned in the upcoming year 2021, that the National Examination will be replaced with the minimum competency assessment and character surveys. (Makdori, 2019) This policy is none other than one of its factors referring to TIMSS. This was conveyed directly by the Minister of Education and Culture, Nadiem Kariem, who said that the direction of this policy also refers to the international level, such as Pisa and TIMSS.

The assessment of the minimum competency scheme and the character survey will be similar to the TIMSS research scheme. The implementation of the minimum competency assessment will be carried out on students in the middle of the school level, for instance it will be carried out for students class 4 at the level of elementary / equivalent, grade 8 at the level of junior high school or equivalent, and grade 11 in senior high school / equivalent.

Based on the background review above, this study is aimed at analysing the national exam questions for Mathematics subject for junior high school / MTs in the academic year $2005 / 2006$ to $2018 / 2019$ based on TIMSS taxonomy as well as analysing the suitability of the questions based on TIMSS taxonomy. The result of this study will be compared to the guidelines set by the government regarding the national examinations. 


\section{Hipotenusa Journal, 3 (1), June 2021 \\ Nur Colis}

\section{METHOD}

Types of Research

This type of research is qualitative research with case study methods. This research will focus on a case study where it emphasizes on the analysis or interpretation of written material based on the context. The written material is the Mathematics questions in the National Examination for Junior High School / MTs academic year 2005/2006 to 2018/2019. The questions will be assessed based on the TIMSS Assessment Framework.

\section{Data sources}

The primary data source of this study is the questions of Mathematics subject in the National Exam for SMP/MTs academic year 2005/2006 to 2018/2019.

\section{Data Collection Technique}

The data for this qualitative research is collected through document analysis technique which consists of data reduction, data presentation, and conclusion. The subject of research in this study is 14 Mathematics National Examination texts for SMP / MTs academic year 2005/2006 up to 2018/2019. The indicators for content and cognitive dimensions used in this study is based on the TIMSS taxonomy. The researchers use triangulation by experts via online FGD (Focus Group Discussion) for the data validation. Data analysis

The data is analysed using Miles \& Huberman model which includes three activities, namely data reduction, data display and conclusions (verification). Data reduction refers to the process of selecting, focusing, simplifying, abstracting, and transforming the data that appear in written up field notes or transcription. Data reduction is carried out to select the data that is needed and to remove unnecessary data so that the research can be proceed to conclusions and verification. The data was presented in the form of a brief description about the results of an analysis of national exam questions so that the researcher will find it easier to understand about what happened and what should be planned. The conclusions will be in the form of description of an object that has been clearly assessed.

The assessments of mathematical and science achievement in TIMSS are categorized in two domains, namely content and cognitive domain by considering to the curriculum applied in the country. The distribution of specifications and assessment is as follows: 


\section{a. Content Domain}

As written in TIMSS Assessment Framework, content dimensions consist of four domains, namely: numbers, algebra, geometry, data and probability. Each domain is detailed further in several topics. The following table shows the students' abilities tested in each domain on the content dimensions (Mullis, I. V. S., Martin, 2019).

Table 1. The Proportion of Students' Abilities Tested on the Content Dimension based on TIMSS

\begin{tabular}{lcl}
\hline \multicolumn{1}{c}{ Domain } & Percentage & \multicolumn{1}{c}{ Topics } \\
\hline Number & $30 \%$ & Whole Number \\
& & Fraction, decimals and even number \\
& Ratio, proportion, and percentage \\
Algebra & $30 \%$ & Algebraic expression dan operation \\
& & Equation and inequalities \\
& & Relations and function \\
Geometry & $20 \%$ & Geometric shape \\
& & Measurement \\
& & Position and transformation \\
& & Characteristic of Data \\
Pata and & $20 \%$ & Interpretation of Data \\
& & Probability \\
\hline
\end{tabular}

b. Cognitive domain

The cognitive dimension consists of three domains, they are knowing, applying and reasoning. Cognitive dimensions are interpreted as the expected behaviours of students when they are dealing with mathematical domain which included in the content dimension. The following table shows the proportion of capabilities tested on cognitive dimensions in TIMSS studies.

Table 2. The Proportion of Students' Abilities Tested on the Cognitive Dimension based on TIMSS

\begin{tabular}{cccc}
\hline Domain & Proportion & \multicolumn{1}{c}{ Topics } \\
\hline Knowing & $35 \%$ & Recall is understanding definitions, properties, \\
& & terminology, and notations in mathematics (example:
\end{tabular}




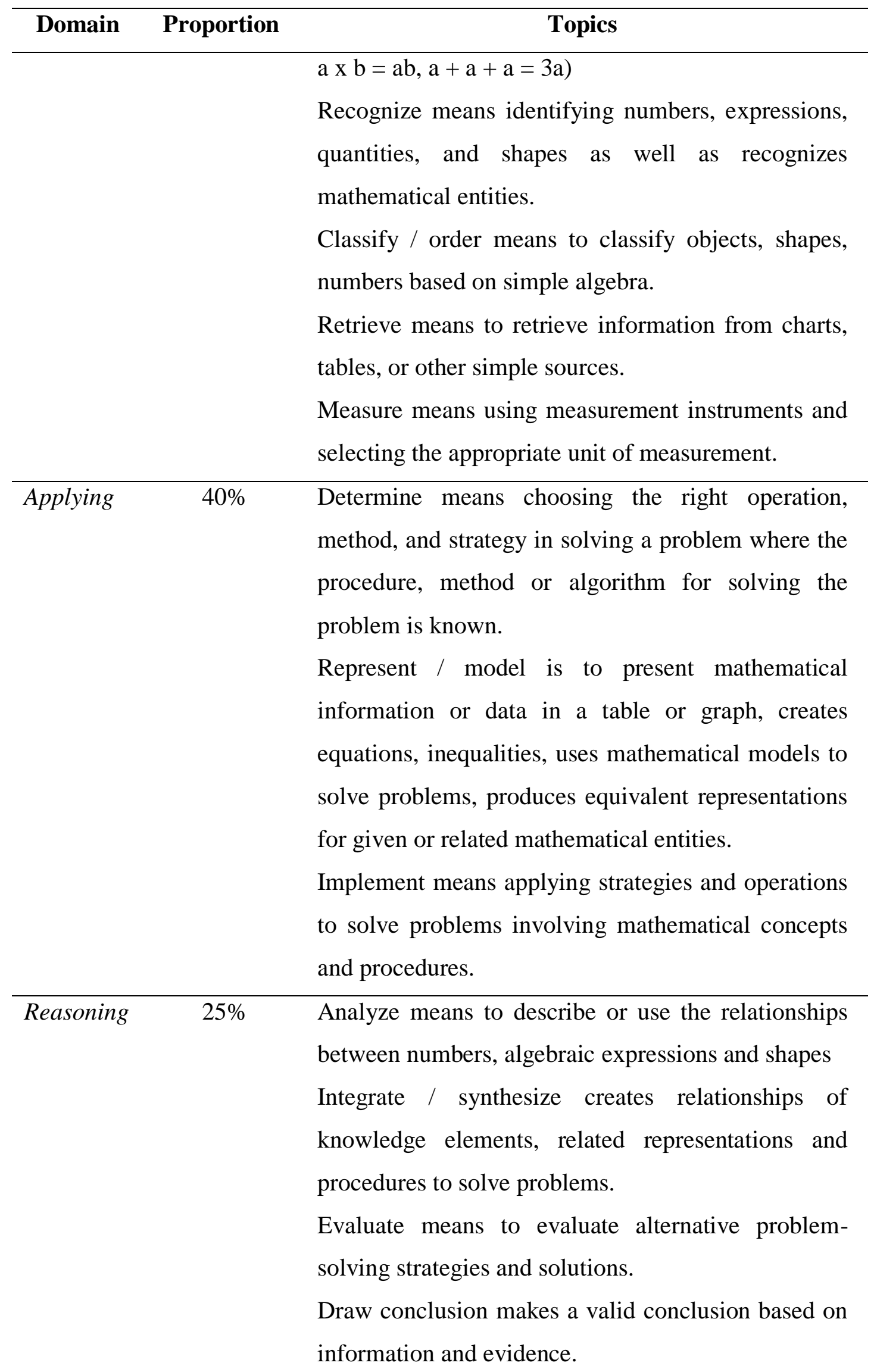




\begin{tabular}{ll}
\hline Domain Proportion & \multicolumn{1}{c}{ Topics } \\
\hline & Generalize creates statements that represent more \\
& general relationship and the broader terms that apply. \\
& Justify provides mathematical arguments to support a \\
& strategy or solution.
\end{tabular}

The study was conducted on a large scale, namely identifying the questions then mapping them based on the prepared guidelines. The data is obtained by measuring the achievement of cognitive aspects in each national exam questions in accordance with the TIMSS research framework. Data is collected by analysing the national exam questions to describe every cognitive aspect of it. The data is then analysed by classifying each of them to describe each aspect contained in the item of the national exam questions based on the TIMSS research framework which is divided into two domains, namely the content and cognitive domain.

\section{RESULTS AND DISCUSSION}

At the analysis phase of the National Examination of Mathematics, the researcher mapped it into two dimensions according to the TIMSS Assessment Framework, namely the content dimensions (content) and cognitive dimensions (knowledge). In the guidelines for making the national exam mathematics questions that have been established by the government are grouped into the scope of the material and cognitive level. In the scope of the material divided into material, algebra, geometry, and statistics and opportunities without being given a clear percentage of material distribution. While at the cognitive level divided into knowledge and understanding levels (25-30\%), application level (50$60 \%)$ and the application level (10-15\%). The division of this percentage is quite flexible but can trigger differences in percentage at each cognitive level because the percentage given is less assertive as in the TIMSS assessment framework.

The result of analysis of the Mathematics National Examination Text for SMP/MTs from academic year 2005/2006 to 2018/2019 on both content and cognitive dimensions based on TIMSS taxonomy can be illustrated in the following graph: 
Hipotenusa Journal, 3 (1), June 2021

Nur Colis

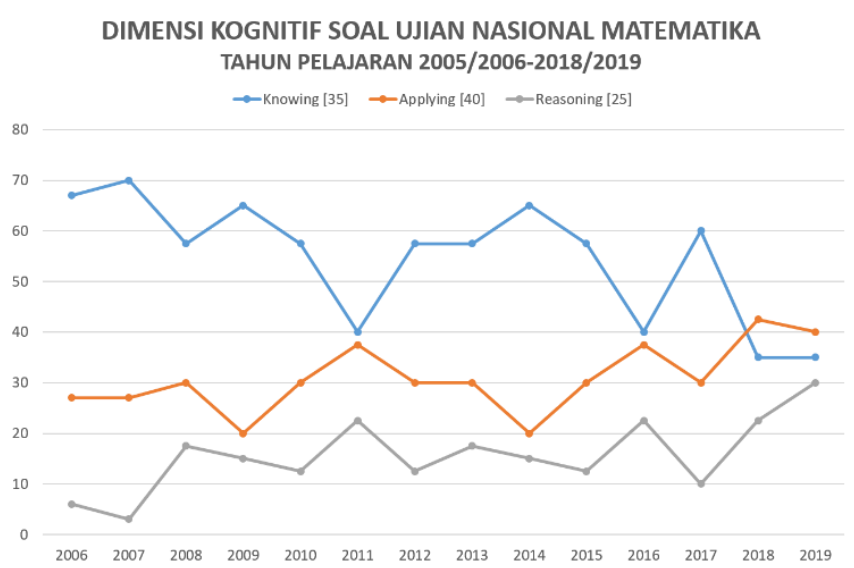

Figure 1. Distribution of Content Dimensions of the Mathematics National

Examinations for SMP/MTs Academic Year 2005/2006 - 2018/2019

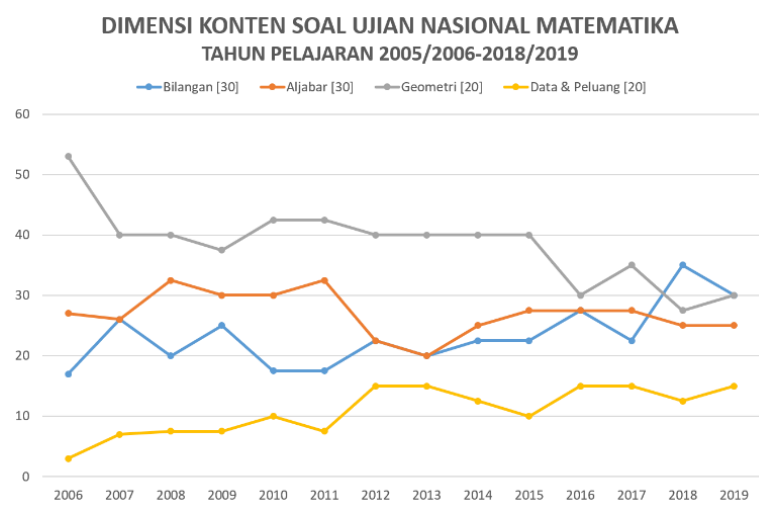

Figure 2. Distribution of Cognitive Dimensions of the Mathematics National

Examinations for SMP/MTs Academic Year 2005/2006 - 2018/2019

Based on the analysis of the Mathematics National Examination Text for SMP/MTs from academic year 2005/2006 to 2018/2019 on both content and cognitive dimensions based on TIMSS taxonomy, the following data can be obtained:

Table 3. Percentage of SMP/MTs Mathematics National Exam Data for Academic Year 2005 / 2006-2018 / 2019

\begin{tabular}{|l|c|c|c|c|c|}
\hline \multirow{2}{*}{ Content Dimension } & \multicolumn{5}{|c|}{ Percentage per year (\%) } \\
\cline { 2 - 6 } & $\mathbf{2 0 0 6}$ & $\mathbf{2 0 0 7}$ & $\mathbf{2 0 0 8}$ & $\mathbf{2 0 0 9}$ & $\mathbf{2 0 1 0}$ \\
\hline Numbers & 17 & 26 & 20 & 25 & 17,5 \\
\hline Algebra & 27 & 26 & 32,5 & 30 & 30 \\
\hline Geometry & 53 & 40 & 40 & 37,5 & 42,5 \\
\hline Data and Probability & 3 & 7 & 7,5 & 7,5 & 10 \\
\hline & & & \\
\end{tabular}


Hipotenusa Journal, 3 (1), June 2021

Nur Colis

\begin{tabular}{|l|c|c|c|c|c|}
\hline Cognitive Dimension & \multicolumn{5}{|l|}{} \\
\hline Knowing & 67 & 70 & 65 & 70 & 65 \\
\hline Applying & 27 & 27 & 27,5 & 25 & 25 \\
\hline Reasoning & 6 & 3 & 7,5 & 5 & 10 \\
\hline
\end{tabular}

\begin{tabular}{|l|c|c|c|c|}
\hline \multirow{2}{*}{ Content Dimension } & \multicolumn{4}{|c|}{ Percentage per year (\%) } \\
\cline { 2 - 5 } & $\mathbf{2 0 1 6}$ & $\mathbf{2 0 1 7}$ & $\mathbf{2 0 1 8}$ & $\mathbf{2 0 1 9}$ \\
\hline Numbers & 27,5 & 22,5 & 35 & 30 \\
\hline Algebra & 27,5 & 27,5 & 25 & 25 \\
\hline Geometry & 30 & 35 & 27,5 & 30 \\
\hline Data and Probability & 15 & 15 & 12,5 & 15 \\
\hline Cognitive Dimension & \multicolumn{4}{|l}{} \\
\hline Knowing & 40 & 60 & 35 & 35 \\
\hline Applying & 37,5 & 30 & 42,5 & 40 \\
\hline Reasoning & 22,5 & 10 & 22,5 & 25 \\
\hline
\end{tabular}

\begin{tabular}{|l|c|c|c|c|c|}
\hline \multirow{2}{*}{ Content Dimension } & \multicolumn{5}{|c|}{ Percentage per year (\%) } \\
\cline { 2 - 6 } & $\mathbf{2 0 1 1}$ & $\mathbf{2 0 1 2}$ & $\mathbf{2 0 1 3}$ & $\mathbf{2 0 1 4}$ & $\mathbf{2 0 1 5}$ \\
\hline Numbers & 17,5 & 22,5 & 20 & 22,5 & 22,5 \\
\hline Algebra & 32,5 & 22,5 & 20 & 25 & 27,5 \\
\hline Geometry & 42,5 & 40 & 40 & 40 & 40 \\
\hline Data and Probability & 7,5 & 15 & 15 & 12,5 & 10 \\
\hline Cognitive Dimension & & & & & \\
\hline Knowing & 60 & 57,5 & 57,5 & 65 & 57,5 \\
\hline Applying & 32,5 & 30 & 30 & 20 & 30 \\
\hline Reasoning & 7,5 & 12,5 & 17,5 & 15 & 12,5 \\
\hline
\end{tabular}

Based on the result above, it can be explained further as follows:

\section{An Analysis of the National Exam questions academic year 2005/2006}

For the content dimension, the results showed that 16 items are questions about geometry (53\%), followed by 8 items about algebra (27\%), 5 items about numbers (17\%), and 1 item about probability (3\%). It can be seen that the data and probability domain 


\section{Hipotenusa Journal, 3 (1), June 2021 \\ Nur Colis}

have the lowest percentage while the geometry domain has the highest percentage. The percentage for geometry domain exceeds more what has been set by the TIMSS taxonomy while number and algebra domain are both closed to the TIMSS taxonomy, while for the data and probability are still far below the determined proportion. It shows that the mapping of the question on content dimension of the Mathematics National Examination for academic year 2005/2006 has not been spread evenly according to TIMSS taxonomy.

From the analysis above, it was obtained that the percentage of the cognitive dimensions are $67 \%$ for knowing with 20 items, $27 \%$ for applying with 8 items and $6 \%$ for reasoning with 2 items. It can be seen that the knowing domain has the highest percentage while the reasoning domain has the lowest percentage. The percentage in the knowing domain exceeded almost double the proportion of TIMSS taxonomy, the applying domain has approached the standard proportion and the reasoning domain was still very far below the standard proportion. This shows that the mapping of cognitive dimensions of the Mathematics National Examination in the academic year 2005/2006 has not been spread evenly according to TIMSS.

\section{An Analysis of the National Exam questions academic year 2006/2007}

The study showed that for the content dimension, about $27 \%$ of the questions are for numbers domain with 8 items of questions, $27 \%$ as well for algebra domain with 8 items, while geometry dominated the questions for about $40 \%$ with 12 items, and $6 \%$ for data and probability domain with 2 items. It can be seen that the data and probability domains have the lowest percentage, and on the contrary, the geometry domain has the highest percentage, and only the algebraic domain that was close to the TIMSS taxonomy. The percentage in the geometry domain exceeded double the proportion of TIMSS taxonomy, while the number and algebra domain approached the standard proportions and data and probability domains were still far below the predetermined proportions. This shows that the mapping of the question on the content dimensions of the Mathematics National Examination for academic year 2006/2007 has not been spread evenly according to TIMSS taxonomy.

The results indicated that in the cognitive domain, about $70 \%$ of questions are dominated by knowing domain with 21 items, followed by $27 \%$ for applying domain with 8 items, and $3 \%$ for reasoning with 1 item. It can be seen that the knowing domain has the highest percentage while the reasoning domain has the lowest percentage. The 
percentage of the knowing domain exceeded double the proportion of TIMSS taxonomy, while the applying domain approached the standard proportions and the reasoning domain was still very far below the specified proportion. This shows that the mapping of the question for the cognitive year has not been spread evenly according to TIMSS taxonomy.

\section{An Analysis of the National Exam questions academic year 2007/2008}

The results of the study showed that the content dimensions consisted of $25 \%$ for the numbers domain with 10 items of question, 32.5\% for algebra domain with 13 items, $40 \%$ for geometry domain with 16 items, and $7.5 \%$ for the data and probability domain with 3 items. It can be seen that the data and probability domains have the lowest percentage while the geometry domain has the highest percentage. The geometry domain exceeded twice the proportion of TIMSS taxonomy, the algebra domain exceeded slightly from the proportion and number domain approached the standard proportions while the data and probability domain was far below the proportion that has been determined. This shows that the mapping of the content dimension in the Mathematics National Examination academic year 2007/2008 has not been spread evenly according to TIMSS.

From the analysis, it can obtained the percentage of the items, and $7.5 \%$ for reasoning with 3 items. It can be seen that the knowing domain has the highest percentage while the reasoning domain has the lowest percentage. The knowing domain exceeded almost double the proportion set by TIMSS taxonomy, the applying domain approached the standard proportion and the reasoning domain was very far below the specified proportion. This shows that the mapping of questions on the cognitive dimension (knowledge) of the Mathematics National Examination of the academic year 2007/2008 has not been spread evenly according to TIMSS taxonomy.

\section{An Analysis of the National Exam questions academic year 2008/2009}

The study showed that distribution of the content dimensions is $25 \%$ for numbers with 10 items of question, $30 \%$ for the algebraic domain with 12 items, $37.5 \%$ for the geometry domain with 15 items, and $7.5 \%$ for the data and probability domain with 3 items. It can be seen that the data and probability domains have the lowest percentage, and on the other hand, the geometry domain has the highest percentage. The percentage of geometry domain exceeded slightly the TIMSS taxonomic proportion, the number domain was closer to the standard proportions, the data and probability domains were far below the predetermined proportions. Only the algebraic domain has a percentage of 
questions in accordance with the TIMSS taxonomic proportions. This shows that the mapping of questions on the content dimension of the Mathematics National Exam academic year 2008/2009 was not evenly distributed according to the TIMSS taxonomy. of the $2008 / 2009$

The result also showed the percentage of cognitive domains. About $70 \%$ was dominated by knowing domain with 28 items of question, $25 \%$ for applying domain with 10 items, and 5\% for reasoning with 2 items. It can be seen that the knowing domain has the highest percentage while the reasoning domain has the lowest percentage. The percentage of the knowing domain exceeded twice the TIMSS taxonomy proportions, the applying domain approached the standard proportions and the reasoning domains were very far below the predetermined proportions. This indicated that the mapping of questions on the cognitive dimension (knowledge) of the National Mathematics Examination for the academic year 2008/2009 has not been evenly distributed according to the TIMSS taxonomy.

\section{An Analysis of the National Exam questions academic year 2009/2010}

The percentage of content dimensions for number domain was $17.5 \%$ with 7 items of questions, and about $30 \%$ for algebraic domain with 12 items, $42.5 \%$ for geometry domain with 17 items, and $10 \%$ for data and probability domain with 4 items. It can be seen that the data and probability domains have the lowest percentage while the geometry domain has the highest percentage. The geometry domain exceeded the TIMSS taxonomy proportion, and the proportion for number domain was still need to be added, while the data and probability domain were still far below the predetermined proportion. Only the algebraic domain has a percentage of questions in accordance with the TIMSS taxonomic proportions. This shows that the mapping of the questions on the content dimensions of Mathematics National Exam academic year 2009/2010 was not evenly distributed according to the TIMSS taxonomy.

From the analysis above, the percentage of knowing domain for cognitive dimension is $65 \%$ with 26 items, followed by $25 \%$ for applying domain with 10 items, and $7.5 \%$ for reasoning with 3 items. It can be seen that the knowing domain has the highest percentage while the reasoning domain has the lowest percentage. The percentage of knowing domain exceeded almost twice the TIMSS taxonomy proportions, the applying domain has approached the standard proportions and the reasoning domains 
were very far below the predetermined proportions. This shows that the mapping of the questions on the cognitive dimension (knowledge) of the Mathematics national exam academic year 2009/2010 has not been evenly distributed according to the TIMSS taxonomy.

\section{An Analysis of the National Exam questions academic year 2010/2011 (Package 15)}

It is showed that $17.5 \%$ of the questions for content domains were for numbers with 7 items, about $32.5 \%$ for algebraic domain with 13 items, $42.5 \%$ for geometry domain with 17 items, and only $7.5 \%$ for data and opportunity domains with 3 items. It can be seen that the data and probability domains have the lowest percentage while the geometry domain has the highest percentage. The percentage in the geometry domain exceeded more than double the proportion set by TIMSS, the algebraic and numbers domain were still less than the proportion set by the TIMSS and the data and probability domains were still far below the predetermined proportion. This indicated that the mapping of the questions on the content dimension of the Mathematics National Exam Package (15) academic year 2010/2011 has not been evenly distributed according to the TIMSS taxonomy.

The result of the study also explained that the percentage of knowing domain in the cognitive dimension was $60 \%$ with 24 items, followed by $30 \%$ for applying domain with 12 items, and $10 \%$ for reasoning with 4 items. It can be seen that the knowing domain has the highest percentage while the reasoning domain has the lowest percentage. The percentage of knowing domain exceeded almost double the TIMSS taxonomy proportions, while the applying domain has approached the standard proportions and the reasoning domains were very far below the predetermined proportions. This indicates that the mapping of questions on the cognitive dimension (knowledge) of the Mathematics National Exam Package (15) academic year 2010/2011 has not been evenly distributed according to the TIMSS taxonomy.

An Analysis of the National Exam questions academic year 2011/2012 (Code: C32)

The findings showed that for the content dimension, about $22.5 \%$ of questions was for number domain with 9 items, $22.5 \%$ as well for algebraic domain with 9 items, $40 \%$ for the geometry domain with 16 items, and $15 \%$ for data and probability domain with 6 items of question. It can be seen that the data and opportunity domains have the lowest percentage while the geometry domain has the highest percentage. The percentage in the 
geometry domain exceeded twice the TIMSS taxonomy proportions, the algebraic and number domain have not reached the determined proportions, while the data and probability domains have approached the determined proportions. This indicated that that the mapping of the questions on the content dimension of the Mathematics National Examination Code (C32) has not been evenly distributed according to the TIMSS taxonomy.

As for the cognitive domain, it was found that $57.5 \%$ of the questions were for knowing domain with 23 items, 32.5\% for applying domain with 13 items, and $12.5 \%$ for reasoning with 5 items. It was showed that the knowing domain has the highest percentage among others, while the reasoning domain has the lowest percentage. The percentage in the knowing domain exceeded the proportions set by the TIMSS taxonomy, the proportion of applying domain almost reached the standard and the reasoning domains were still less than the determined proportion. This showed that the mapping of questions on the cognitive dimension of the Mathematics National Examination Code (C32) academic year 2011/2012 has not been evenly distributed according to the TIMSS taxonomy.

\section{An Analysis of the National Exam questions academic year 2012/2013}

The findings of this study indicated that, for the content domain, $20 \%$ of the questions were for numbers with 8 items, $20 \%$ for algebraic domain with 8 items, $45 \%$ for geometry domain with 18 items, and $15 \%$ for data and probability domain with 6 items. It can be seen that the data and probability domains have the lowest percentage while the geometry domain has the highest percentage. The percentage in the geometry domain has exceeded twice the proportion set by TIMSS taxonomy, while the data and probability domains almost reached the determined proportions. Only the numbers and algebraic domains that were already in accordance with the standard from TIMSS taxonomy. This showed that the mapping of the questions on the content dimension of the Mathematics National Exam in 2012/2013 was almost evenly distributed according to the TIMSS taxonomy.

While for the cognitive domain, about $32.5 \%$ of the questions were for knowing domain with 13 items, 55\% for applying domain with 22 items, and $12.5 \%$ for reasoning with 5 items. It showed that the knowing domain has the highest percentage while the reasoning domain has the lowest percentage. The percentage in the knowing domain has 
exceeded the TIMSS taxonomy proportions, while the applying domain almost reached the standard proportion and the reasoning domain was still need to be added. This showed that the mapping of the questions on the cognitive dimension of the Mathematics National Exam academic year 2012/2013 has not been evenly distributed according to the TIMSS taxonomy.

\section{An Analysis of the National Exam questions academic year 2013/2014}

The findings showed that for the content dimension, approximately $22.5 \%$ were for numbers domain with 9 items, $20 \%$ for algebraic domain with 20 items, $40 \%$ for geometry domain with 16 items, and $12.5 \%$ for the data probability domain with 5 items. It can be seen that the percentage of data and opportunity domains have the lowest percentage, and on the contrary, the geometry domain has the highest percentage. The percentage in the geometry domain exceeded double the TIMSS taxonomy proportion, while the number and algebraic domain were still less than the proportion, and the data and probability domains has approached the determined proportions. This showed that the mapping of questions on the content dimensions of the Mathematics National Exam academic year 2013/2014 has not been evenly distributed according to the TIMSS taxonomy.

While for the cognitive domains, most of the questions (65\%) were for knowing with 26 items, $20 \%$ for applying domain with 8 items, and $15 \%$ for reasoning with 6 items. It can be seen that the knowing domain has the highest percentage while the reasoning domain has the lowest percentage. The percentage of knowing domain exceeded nearly double the TIMSS taxonomy proportions, and the applying domain was still far from the standard proportions, while the reasoning domain has approached the determined proportion. This showed that the mapping of questions on the cognitive dimension of the Mathematics National Exam in academic year 2013/2014 has not been evenly distributed according to the TIMSS taxonomy.

\section{An Analysis of the National Exam questions academic year 2014/2015}

The result of the study showed that for the content dimensions, $22.5 \%$ of the questions were for numbers domain with 9 items, $27.5 \%$ for algebra domain with 11 items, $40 \%$ for geometry domain with 16 items, and $10 \%$ for data and probability domain with 4 items. It can be seen that the data and opportunity domains have the lowest percentage while the geometry domain has the highest percentage. The percentage of the geometry domain exceeded double proportion set by the TIMSS taxonomy, the numbers 
and algebra domains were closer to the standard proportions, while the data and probability domains were still less than the specified proportions. This indicated that the mapping of the questions on the content dimensions of the Mathematics National Exam academic year 2014/2015 has not been evenly distributed according to the TIMSS taxonomy.

While for the cognitive dimensions, more than half of the questions $(57.5 \%)$ came from the knowing domain with 23 items, followed by $32.5 \%$ for applying domain with 13 items, and $12.5 \%$ for reasoning with only 5 items. It can be seen that the knowing domain has the highest percentage while the reasoning domain has the lowest percentage. The percentage of the knowing domain exceeded the TIMSS taxonomy proportions, while applying and reasoning domains almost reached the standard proportions. This showed that the mapping of questions on the cognitive dimension of the Mathematics National Exam academic year 2014/2015 has not been evenly distributed according to the TIMSS taxonomy.

\section{Analysis of the National Exam questions academic year 2015/2016}

It was found in this study that approximately $27.5 \%$ of the questions were for numbers domain with 11 items, $27.5 \%$ for algebra domain with 11 items, 30\% for the geometry domain with 12 items, and 15\% for data and probability domain with 6 item question. It can be seen that the data and opportunity domains have the lowest percentage while the geometry domain has the highest percentage. The percentage of the geometry domain exceeded the TIMSS taxonomy proportions, while the number, algebra, the data and domains almost reached the standard proportions. This showed that the mapping of questions on the content dimensions of the Mathematics National Exam academic year 2015/2016 has not been evenly distributed according to the TIMSS taxonomy.

As for the cognitive dimensions, $40 \%$ of the questions were for knowing domain with 16 items, $37.5 \%$ for applying domain with 15 items, and $22.5 \%$ for reasoning with 9 items. It indicated that the knowing domain has the highest percentage while the reasoning domain has the lowest percentage. The percentage of the knowing domain exceeded the TIMSS taxonomy proportions, while the applying and reasoning domain almost reached the standard proportions. This showed that the mapping of questions on the cognitive dimension of the Mathematics National Examination academic year 202015/2016 was almost evenly distributed according to the TIMSS taxonomy. 


\section{An Analysis of the National Exam questions academic year 2016/2017}

For the content dimensions, about $22.5 \%$ of the questions were for numbers domain with 9 items, $27.5 \%$ for the algebra domain with 11 items, $35 \%$ for geometry domain with 14 items, and $15 \%$ for data and probability domain with 6 items. It can be seen that the data and opportunity domains have the lowest percentage while the geometry domain has the highest percentage. The percentages in the geometry domain exceeded the TIMSS taxonomy proportions, while the numbers, algebra and data and probability domains almost reached the standard proportions. This indicated that the mapping of questions on the content dimensions of the Mathematics National Exam academic year 2016/2017 was almost evenly distributed according to the TIMSS taxonomy.

As for the cognitive dimensions, approximately $60 \%$ of the questions were for knowing domain with 24 items, $15 \%$ for applying domain with 12 items, and $10 \%$ for reasoning with 4 items. Meaning that the knowing domain has the highest percentage while the reasoning domain has the lowest percentage. The percentage of knowing domain exceeded the TIMSS taxonomy proportions, while the applying and reasoning domains almost reached the specified proportions. This showed that the mapping of questions on the cognitive dimension of the Mathematics National Exam in the academic year of 2016/2017 has not been evenly distributed according to the TIMSS taxonomy.

\section{An Analysis of the National Exam questions academic year 2017/2018}

The result of this study showed that for content dimensions, about $35 \%$ of questions were for numbers domain with 14 items, $25 \%$ for algebraic domain with 10 items, $27.5 \%$ for geometry domain with 11 items, and $12.5 \%$ for data and probability domain with 5 items. It can be seen that the data and opportunity domains have the lowest percentage while the number domain has the highest percentage. The percentages in the number and geometry domains exceeded the TIMSS taxonomy proportions, the algebra domain almost reached the standard proportions, so do the data and probability domains. This showed that the mapping of questions on the content dimensions of the Mathematics National Exam academic year 2017/2018 was not evenly distributed according to the TIMSS taxonomy.

While for the cognitive dimensions, about $35 \%$ were for the knowing domain with 14 items, $42.5 \%$ for applying domain with 17 items, and $22.5 \%$ for reasoning with 9 items. It indicated that the applying domain has the highest percentage while the 
reasoning domain has the lowest percentage. The percentage of applying domain slightly exceeded TIMSS taxonomy proportion, while reasoning domain almost reached the standard proportion. Only the knowing domain has reached the determined proportion by TIMSS. This showed that the mapping of questions on the cognitive dimension of the Mathematics National Exam academic year 2017/2018 was almost evenly distributed according to the TIMSS taxonomy.

\section{An Analysis of the National Exam questions academic year 2018/2019}

The findings of the study showed that $30 \%$ of the questions on the content dimensions were for numbers domain with 12 items, $25 \%$ for algebraic with 10 items, $30 \%$ for geometry domain with 12 items, and $15 \%$ for data and probability domain with 6 items. It can be seen that the data and opportunity domains have the lowest percentage, while the algebraic and geometry domains have the highest percentage. The percentages in the geometry domain has exceeded the TIMSS taxonomy proportions, while the algebra and data and probability domains almost reached the standard proportions. Only the algebra domain has the percentage of questions that matched the proportion set by TIMSS. This showed that the mapping of the questions on the content dimensions of the Mathematics National Exam academic year 2018/2019 was almost evenly distributed according to the TIMSS taxonomy.

For the cognitive dimensions, about 35\% were for knowing domain with 14 items, $40 \%$ for applying domain with 16 items, and $25 \%$ for reasoning domain with 10 items. The percentage in all cognitive domains was in accordance with the TIMSS taxonomy proportion. This showed that the mapping of questions in the cognitive dimension of the Mathematics National Exam academic year 2018/2019 has been evenly distributed according to the TIMSS taxonomy.

The results of the analysis of the National Mathematics Examination questions for the academic year 2005/2006 to 2018/2019 were classified in two different dimension, namely the content and cognitive dimension. In the content dimension, it consists of number domain (30\%), algebraic domain (30\%), geometry domain (20\%), and data and probability domain $(20 \%)$. The study also indicated that the geometry domain in the Mathematics National Exam has exceeded the proportion set by TIMSS (30\%). It affected on the data and probability domains which only have very small distribution in the exam and it was far below the standard set by TIMSS, which is $20 \%$ or 8 items of questions. 
While the distribution of number domain in the national exam is fairly good because percentage of this domain almost reach the proportion set by the TIMSS. The algebraic domain has a better distribution of questions than the others because it has a percentage of questions that are not far from the proportions set by TIMSS.

The result of the study about the cognitive dimension of the Mathematics National Examination questions for the academic year 2005/2006 to 2018/2019 were divided into three, namely the knowing, applying and reasoning domain with a percentage of $35 \%$, $40 \%$, and $25 \%$ respectively. The results showed that the knowing domain has the highest distribution of questions compared to the others. This domain always exceeded the minimum proportion determined by TIMSS, or sometimes doubled. This affected the distribution of reasoning domain which only has a very small percentage of questions, which is far from the proportions set by TIMSS. Meanwhile, the applying domain has a fairly good distribution of questions compared to others because the percentage of its questions from year to year is quite stable, approaching the TIMSS proportion. The data obtained in this study is supported by the results of International Benchmark of TIMSS in 2011 conducted by Erika Afiani (2012: 103) which concluded that the aimed cognitive domain was not explicitly indicated, in contrast to the cognitive aspects targeted by TIMSS. Indah Fitri and Budi Murtiyasa (2017) also conveyed the same thing that the mapping of the junior high school mathematics national exam questions for the academic year 2015/2016 was not in accordance with the target of TIMSS in 2015.

The content scope and cognitive level of national exam questions is in accordance with the guidelines set by government. The content scope consisted of numbers, algebra, geometry, and data and probability. Similar to the TIMSS taxonomy, the content dimensions are divided into numbers (30\%), algebra (30\%), geometry (20\%), data and statistics (20\%). In the content scope, the government did not mention the clear percentage of each domain so that the distribution of each domains were not the same every year. In the 2019, 2018, and 2017 National Examinations, the percentage of content scope was different from the results of the researcher's analysis. It can be seen in the 2019 National Examination that the distribution of algebraic material from the government was $22.5 \%$, and geometry was $32.5 \%$, that was different from the findings of this study which were $25 \%$ and $30 \%$ respectively. At the 2018 National Examination, the government has determined for the algebraic material that should be $27.5 \%$ and geometry at $25 \%$, but it 
was different from the findings of researchers in this study that were $25 \%$ and $27.5 \%$ respectively. And at the 2017 National Examination, the government has set algebraic material at $25 \%$ and geometry at $37.5 \%$, but it is different from the findings of researchers in this research which were $27.5 \%$ and 35\% respectively. Meanwhile, in the 2016 and 2015 National Examination, the distribution set by government is in accordance with the findings of this study, namely the material on numbers, algebra, geometry, data and probability with percentage of $27.5 \%, 27.5 \%, 30 \%, 15 \%$ respectively. In 2016 and $22.5 \%$, $27.5 \%, 40 \%, 10 \%$ in 2015 . The proportion of questions that was not set clearly by the government makes it difficult for both teachers and students to predict the questions in the national examination. This issue might as well confused the educators in helping the students to succeed in the national examination because the government did not determine the percentage of material in detail and clearly even though the material guidelines has been given.

The result of this study is in accordance with the study carried out by Erika Sandrayani, Budi Murtiyasa, and Masduki (2012) who revealed that the weakness of the Mathematics National Examination questions for SMP/MTs in the academic year 2009/2010 and 2010/2011 lies in the level of difficulty of the questions themselves. These questions are too contextual, dominated by cognitive aspects. This shows that students were only asked to do calculations while the formulas/instructions given in the questions have clear directions so that students were not trained to use their reasoning, logic and analytical skills.

Regardless of material set by the government, the questions in the national examinations were still dominated by the geometry domain which exceeded double proportion set by the TIMSS taxonomy, followed by the algebra domain which sometimes exceed the proportion, while the numbers domain was always below the TIMSS proportion and the data and opportunity domain was far below the standard proportion. However, the mapping of content dimensions on the National Examination from the academic year 2005/2006 to $2018 / 2019$ has gradually approached the standard proportions set by TIMSS. This indicated by the findings of each domain of the content dimensions, namely numbers, algebra, geometry, data and probability in the 2006 National Examination, they were 17\%, 27\%, 53\%, 3\%, the 2013 National Examination were $20 \%, 20 \%, 40 \%, 15 \%$, and in the 2018 National Examination they were $35 \%, 25 \%$, 
$27.5 \%, 12.5 \%$ and in the 2019 National Examination were $30 \%, 25 \%, 30 \%, 15 \%$ respectively.

The cognitive levels, which determined by the government, were categorised in three levels, they are knowing and understanding (25-30\%), application (50-60\%), and applying (10-15\%). Similarly, in TIMSS, the cognitive dimension is divided into three as well, namely the knowing or knowledge domain (35\%), the applying domain (40\%) and the reasoning domain (25\%). The findings about cognitive dimensions were quite different. In the 2019 National Examination, the findings in the knowing, applying, and reasoning domains were 35\%,40\%, and 25\%, respectively. At the 2018 National Examination, the respective domains were 35\%, 42.5\%, 22.5\%. In the 2017 National Examination, the respective domains were 60\%, 30\%, 10\%. In the 2016 National Examination, the respective domains were $40 \%, 37.5 \%, 22.5 \%$. And in 2015, the respective domains were $57.5 \%, 30 \%, 12.5 \%$. Thus it can be seen that the government guidelines, that should be dominated by the questions about applying domain for $50-60 \%$, were dominated by the knowing domain from TIMSS which equivalent to the level of knowledge and understanding from the government. This difference occurred because of differences in perceptions between the government's cognitive level and the TIMSS cognitive dimension. The knowing domain, TIMSS has a definition that is similar to the level of application from the government, so that the results of the analysis showed that the knowing domains dominated the questions. This is shown in the fraction story questions, at the cognitive level, the government considers the questions to be at the application level, while TIMSS categorised it in knowing domain. Therefore, the findings of this study found the differences between what has been set by the TIMSS and the government.

Apart from the government's cognitive level guideline, the Mathematics National Examination questions based on the TIMSS taxonomy are still dominated by the knowing domain, while the applying domain is always close to the TIMSS proportion, while the reasoning domain is at still far from the TIMSS proportion. However, the mapping of the cognitive dimensions of the Mathematics National Examination from the academic year $2005 / 2006$ to $2018 / 2019$ has gradually approached the proportions set by TIMSS. This is shown in the 2006 National Examination, the finding of the knowing, applying, and reasoning domains were 67\%, 27\%, 6\%, respectively, at the 2013 National Examination 
$57.5 \%, 30 \%, 17.5 \%$, respectively, at the 2018 National Examination respectively. - 35\%, $42.5 \%, 22.5 \%$ respectively and in the 2019 National Examination the most in accordance with the TIMSS proportion, namely knowing 35\%, applying $40 \%$ and reasoning $25 \%$.

\section{CONCLUSION}

The analysis of Mathematics National Exam questions for junior high school/MTs' academic year 2005/2006 - 2018/2019 based on the TIMSS taxonomy showed that the percentage distribution of both content and cognitive dimensions was still not in accordance with the TIMSS Assessment Framework. In the content dimension, the questions are dominated by the geometry while the questions about data and probability domain are only a few. Meanwhile, the algebraic and number domains are close to the proportions set by TIMSS. For the cognitive domain, the distribution of questions is dominated by the knowing domain, while the reasoning domain has a very small percentage of questions. Meanwhile, the applying domain is quite stable and close to the proportion that has been determined by TIMSS.

The mapping of cognitive level of Mathematics questions for junior high school/MTs's National Exam from the academic year 2005/2006 to 2018/2019 which is set by the government is much different from the TIMSS taxonomy due to differences in definitions at each cognitive level. For example, several questions are categorized by the government as applying domain but they are categorized as knowing domain by the TIMSS. Meanwhile, the government did not set clearly the proportion of the materials for the National Exam. The suitability of the content and cognitive domains on the Mathematics questions based on the TIMSS taxonomy gradually approaches the proportions set by TIMSS. It seems that there is an increase in the percentage approaching the proportion according to the TIMSS Assessment Framework. Over the years, there is an increase towards what has been set by the TIMSS. It can be seen in the percentage of each domain that is close to the proportion set by TIMSS both on the content and cognitive dimensions.

Based on the conclusions above, the writer can provide some suggestions as follows: 1) For other researchers, this research instrument can be used as a consideration to assess the national exam questions more deeply as an effort to develop higher quality questions, 2) For educational evaluators, the results of this study can be used as a 
reference in determining the criteria for developing questions to improve the mathematics achievement of students in Indonesia both domestically and internationally.

\section{REFERENCES}

Aminah, A. N. (2021). Kemendikbud Sebut Tingkat Kesulitan Soal UN Tidak Berubah. www.Republika.co.id.

https://republika.co.id/berita/pendidikan/eduaction/popr4s384/kemendikbud-sebuttingkat-kesulitan-soal-un-tidak-berubah

Asrul, Ananda, R., \& Rosinta. (2014). Evaluasi Pembajalaran. In Ciptapustaka Media.

Badan Standar Nasional Pendidikan. (2017). Buku Saku UN. https://bsnpindonesia.org/wp-content/uploads/2018/03/Buku-Saku-UN-6-Des-2017-Edit-21Maret-2018.pdf

Damaledo, Y. D. (2019). Ujian Nasional Dihapus Mendikbud dan Sejarahnya di Indonesia. Www.Tirto.Id. https://tirto.id/ujian-nasional-dihapus-mendikbud-dansejarahnya-di-indonesia-enkH

Fahmi, A. (2011). Desain Model Sistem Ujian Online. Seminar Nasional Teknologi Informasi \& Komunikasi Terapan 2011 (Semantik 2011), 2011(Semantik), 1-15.

Hadi, S., \& Novaliyosi. (2019). TIMSS Indonesia (Trends in International Mathematics and Science Study). Prosiding Seminar Nasional \& Call For Papers Program Studi Magister Pendidikan Matematika Universitas Siliwangi, 562-569.

Lestari, S. D. (2018). Implementasi Pendekatan Ilmiah pada Pembelajaran Matematika di Kelas VII SMPN 3 Mranggen Tahun Ajaran 2013 /2014. 1(20), 309-317.

Makdori, Y. (2019). Mengenal Konsep Asesmen Kompetensi Minimum Pengganti Ujian Nasional.

Www.Liputan6.Com. https://www.liputan6.com/news/read/4131579/mengenal-konsep-asesmenkompetensi-minimum-pengganti-ujian-nasional\#: :text=Mendikbud telah menyiapkan pengganti UN,minimal yang dibutuhkan para siswi.

Mawarni, Y. E. (2020). Analisis Isi Buku Matematika Kurikulum 2013 Smp Kelas Viii Semester 1 Berdasarkan Taksonomi Timss. Jurnal VARIDIKA, 31(2), 9-20. https://doi.org/10.23917/varidika.v31i2.10214

Mullis, I. V. S., Martin, M. O. (2019). TIMSS 2019 Mathematics Assessment Framework. TIMSS Assessment $2019 \quad$ Frameworks. http://timssandpirls.bc.edu/timss2019/frameworks/ 
Prasetyo, D. A. B., \& Rudhito, M. A. (2016). Analisis Kemampuan dan Kesulitan Siswa SMP dalam Menyelesaikan Soal geometri Model TIMSS. Jurnal Pengajaran MIPA, 21(2), 122-128.

Prastowo, A., Kurikulum, T., Dasar, P., Menengah, D. A. N., Indonesia, D. I., \& Prastowo, A. (2018). JIP:Jurnal Ilmiah PGMI Volume 4 No 2, Desember 2018 Transformasi Kurikulum Pendidikan Dasar..... Andi Prastowo. 4(2), 111-125.

Pratiwi, I. (2016). Pengembangan Soal Matematika Berkarakteristik Timss Tipe Pemecahan Masalah Pada Topik Geometri Pengukuran Volume Kubus Dan Balok Kelas Viii. June.

Sumaryono. (2016). Prosiding Seminar Nasional Pendidikan Matematika. Journal for Research Mathematics Education, 28(1), 331-354. https://www.jstor.org/stable/749784?read-now=1\&seq=1\#page_scan_tab_contents Wulan, E. R., \& Rusdiana. (2013). Buku Evaluasi Pembelajaran. Pustaka Setia. www.pusmenjar.kemdikbud.go.id. (2019a). Laporan Hasil Ujian Nasional. https://pusmenjar.kemdikbud.go.id/hasil-un/ www.pusmenjar.kemdikbud.go.id. (2019b). Ujian Nasional. https://pusmenjar.kemdikbud.go.id/ujian-nasional-un/ 